\title{
Measuring quality of life among people living with HIV: a systematic review of reviews
}

Vanessa Cooper ${ }^{1 *}$ (D), Jane Clatworthy ${ }^{1}$, Richard Harding ${ }^{2}$, Jennifer Whetham ${ }^{1}$ and Emerge Consortium

\begin{abstract}
Aim: A systematic review of reviews was conducted to identify and appraise brief measures of healthrelated quality of life (HRQoL) that have been used in peer-reviewed research with people living with HIV.

Methods: The review was conducted in two stages: 1) search of electronic databases to identify systematic reviews of tools used to measure HRQoL in adults living with HIV, published since the year 2000; 2) selection of HRQol scales from those identified in the reviews. Inclusion criteria included scales that could be self-administered in 10 min or less, covering at least 3 domains of quality of life (physical function, social/role function and mental/ emotional function). For generic scales, inclusion criteria included the availability of normative data while for HIVspecific scales, patient input into the development of the scale was required.
\end{abstract}

Results: Ten reviews met the inclusion criteria. Nine generic scales met the inclusion criteria: the EuroQol five dimensions questionnaire (EQ-5D); Health Utilities Index; McGill Quality of Life questionnaire; Medical Outcomes Study (MOS) Short Form (SF)-12; SF-36; World Health Organisation Quality of Life (WHOQOL- BREF), Questions of Life Satisfaction (FLZM) and SF-20. Available psychometric data supported the EQ-5D and SF-36. Seven HIV-specific scales met the inclusion criteria: the AIDS Clinical Trials Group (ACTG)-21; HIV-QL-31; MOS-HIV; Multidimensional Quality of Life Questionnaire for Persons with HIV/AIDS (MQOL-HIV), PROQOL-HIV, Symptom Quality of Life Adherence (HIV-SQUAD) and the WHOQOL-HIV BREF. Of the HIV -specific measures, the MOS-HIV was considered to have the most well-established psychometric properties, however limitations identified in the reviews included insufficient input from people living with HIV in the development of the scale, cross-cultural relevance and continued applicability. Two relatively new measures, the WHOQOL-HIV BREF and PROQOL-HIV, were considered to have promising psychometric properties and may have more relevance to people living with HIV.

Conclusion: The findings highlight the need for further validation of HRQoL measures in people living with HIV. The choice of one measure over another is likely to be influenced by the purpose of the quality of life assessment and the domains of HRQoL that are most relevant to the specific research or clinical question.

Keywords: Quality of life, HIV, Systematic review, Validity, Reliability

\footnotetext{
* Correspondence: vanessaleecooper@gmail.com

${ }^{1}$ The Lawson Unit, Brighton and Sussex University Hospitals NHS Trust,

Eastern Road, Brighton BN2 1HS, UK

Full list of author information is available at the end of the article
}

(c) The Author(s). 2017 Open Access This article is distributed under the terms of the Creative Commons Attribution 4.0 International License (http://creativecommons.org/licenses/by/4.0/, which permits unrestricted use, distribution, and reproduction in any medium, provided you give appropriate credit to the original author(s) and the source, provide a link to the Creative Commons license, and indicate if changes were made. The Creative Commons Public Domain Dedication waiver (http://creativecommons.org/publicdomain/zero/1.0/) applies to the data made available in this article, unless otherwise stated. 


\section{Background}

Combination antiretroviral therapy (ART) has changed HIV from a terminal disease to a chronic condition in countries where treatment is widely available. With appropriate treatment, people with HIV can now have a near-normal life-expectancy [1]. However, people with HIV continue to have substantially lower health-related quality of life (HRQoL) than the general population, even where the majority of those living with HIV have virological control and are immunologically stable [2]. Evidence suggests that in addition to the underlying infection, social circumstances, relationship issues, comorbidities and stigma may impact on HRQoL in people with HIV [3].

HRQoL is a multidimensional construct concerned with the impact of health on an individual's perception of their wellbeing and level of functioning in important areas of their life [4]. There is a lack of consensus regarding the specific dimensions of quality of life [5]. The constitution of the World Health Organisation, adopted in 1946, states that "Health is a state of complete physical, mental and social well-being" [6]. Reflecting this, health related quality of life is often conceptualised as having physical, mental and social domains [7]. Concepts such as independence, spirituality and environmental factors are also considered relevant [8].

Improving quality of life is central to the care and support of people with HIV [9]. Evaluations of new treatments and interventions to improve healthcare require the measurement of HRQoL as well as clinical endpoints (CD4 count, viral load, progression to AIDS). Valid, reliable and responsive tools are required to evaluate the impact of these interventions on HRQoL. To date there have been a number of reviews conducted to identify and assess measures of HRQoL in people with HIV, but these reviews have had diverse aims. For example, some have looked only at specific pre-selected measures (MOS-HIV and EQ$5 \mathrm{D}$ [10]) or measures that have been applied in a specific context (e.g. clinical trials [4, 11], developed countries [12], or sub-Saharan Africa [13]). The aim of this review is to identify brief, validated, pragmatic tools for appropriate assessment of HRQoL in HIV interventions and routine clinical care. It was not our intention to analyse the measurement properties of HRQoL tools, but to synthesise the findings of existing reviews.

\section{Method}

The methodology was based on published recommendations for conducting systematic reviews of reviews [14]. As there was no specific guidance available for reporting on systematic reviews of reviews, the PRISMA guidelines [15] were used as a guide.

\section{Search strategy}

Papers were identified in two ways:

1) Four online databases (Cochrane Database of Systematic Reviews, Database of Abstracts of Reviews of Effects, Medline, PsycINFO) were searched using the terms listed in Table 1.

2) Hand searching of reference lists of reviewed papers.

The searches were conducted in February 2016. Searches were limited to studies published since year 2000. No language limits were set at this stage.

References of identified articles were exported to EndNote and deduplicated. The references and abstracts were then exported into an Excel spreadsheet for abstract review. All abstracts were reviewed independently by two researchers (JC, VC) to identify potentially relevant papers. Disagreement was resolved through discussion and adjudication by RH and JW. Full text copies of papers that appeared relevant were obtained and subjected to further scrutiny by the two reviewers.

\section{Inclusion and exclusion criteria}

Papers were included in the review if they met the following criteria:

\section{Inclusion criteria}

Criterion 1: the paper reviewed tools that had been used to measure quality of life among adults living with HIV.

Criterion 2: the paper reported findings from a literature review that reported a systematic search strategy.

\section{Exclusion criteria}

Criterion 1: the review reported on HRQoL measures in children/adolescents.

Criterion 2: the review was published prior to 2000. We were interested in the assessment of quality of life of people living with HIV after the introduction of highly active antiretroviral therapy (HAART) in 1996. The year 2000 was selected to allow for the conduct and publication of both individual empirical articles and subsequent review papers capturing HRQoL in the HAART era.

Criterion 3: conference abstract

Criterion 4: focused on quality of life in relation to a specific comorbidity/ treatment side effects (e.g. lipodystrophy).

\section{Analysis}

The search was recorded using the PRISMA flowchart [15]. Two researchers (JC, VC) independently extracted the following data from the papers, where available: the 
Table 1 Search Terms

\begin{tabular}{|c|c|c|c|}
\hline HIV & Quality of Life & Measure $^{a}$ & Review \\
\hline \multirow{2}{*}{$\begin{array}{l}\text { Human } \\
\text { Immunodeficiency Virus }\end{array}$} & QoL & Inventor $^{\mathrm{a}}$ & \\
\hline & PROM & Scale $e^{a}$ & \\
\hline \multirow[t]{7}{*}{ Antiretroviral $^{a}$} & \multirow{7}{*}{$\begin{array}{l}\text { Patient Reported } \\
\text { Outcome }\end{array}$} & Questionnaire & \\
\hline & & Self-report ${ }^{a}$ & \\
\hline & & Assessment ${ }^{a}$ & \\
\hline & & Survey ${ }^{a}$ & \\
\hline & & Tool $^{\mathrm{a}}$ & \\
\hline & & Indicator ${ }^{a}$ & \\
\hline & & Instrument ${ }^{a}$ & \\
\hline
\end{tabular}

Notes Terms within columns were combined with 'OR', terms between columns were then combined with 'AND'

Denotes truncation

aim of the review, dates of the search, databases and other sources searched, search terms, language restrictions, the number of papers reviewed, the generic and HIV-specific HRQoL measures identified.

In order to assess the quality of the reviews, two reviewers $(\mathrm{JC}, \mathrm{VC})$ independently applied existing quality criteria [16] that assess: 1) research question 2) eligibility criteria 3) search strategy, 4) selection of papers, 5) quality assessment 6) presentation of data 7) publication bias 8) heterogeneity. Disagreement was resolved through discussion.

\section{Inclusion of HRQoL measures for the review}

The second stage of the review involved the selection of appropriate HRQoL measures from those identified in the reviews. A similar approach to that taken by Clayson et al. (2006) [4] was adopted, in order to identify comprehensive yet pragmatic tools for assessing HRQoL in HIV interventions and clinical care. Measures were deemed appropriate if they met the following criteria:

- Content: Coverage of at least three core domains of HRQoL: physical function, social/role function and mental/emotional health. In addition patient input was required in the development of HIV-specific measures, in order to reflect patients' experience of disease.

- Practicality: Measures needed to be selfadministered and typically completed within $10 \mathrm{~min}$. Where completion time data were not available, we included measures with less than 40 items. This cut-off was based on an estimation of completion rates drawing on the data available in the reviews, indicating approximately four items per minute.
- Normative data: For generic measures, normative data needed to be available to allow comparison between people with HIV and the general population.

Information on each of the selected measures was then obtained from the reviews. This included the HRQoL domains addressed, number of items, type of scale, accessibility (e.g. availability in different languages, availability of population preference rates for generic measures, approximate time taken to complete the measure), reliability, validity (including responsiveness) and conclusions/recommendations made within the reviews.

\section{Results}

Figure 1 shows the PRISMA flowchart. The electronic database search identified 544 papers. After removal of duplicates, 278 abstracts were subjected to review. After applying our inclusion and exclusion criteria, 27 articles were obtained and subjected to full text review. Of those, 9 met the inclusion criteria. One further study was identified through the reference list search.

\section{Overview of the published systematic reviews}

Characteristics of the reviews are summarised in Table 2. The search periods for the published systematic reviews addressed the period 1995-2013 (6 studies did not record the dates of the search and one study did not record the start date). Four reviews were restricted to abstracts/ papers published in the English language [3, 10-12], one was restricted to papers published in English or Spanish [17], one had no language restrictions [18] and the remaining 4 reviews did not state whether or not the review was restricted by language $[4,13,19,20]$. The number of articles reviewed ranged from 26 to 852 (six did not specify the number of articles reviewed). The number of generic HRQoL measures identified by the reviews ranged from 0 to 23 (median $=7$ ) and the number of HIV specific measures identified ranged from 1 to $18($ median $=11)$.

\section{Quality of the reviews}

The results of the quality assessment [16] are shown in Table 3. Eight of the ten reviews clearly stated a well formulated research question. Four of the ten reviews had predefined and specified their inclusion and exclusion criteria, and 4 had conducted a comprehensive search including multiple scientific literature databases and manual searches of references. None of the reviews stated that at least two researchers had conducted an independent review of titles, abstracts 


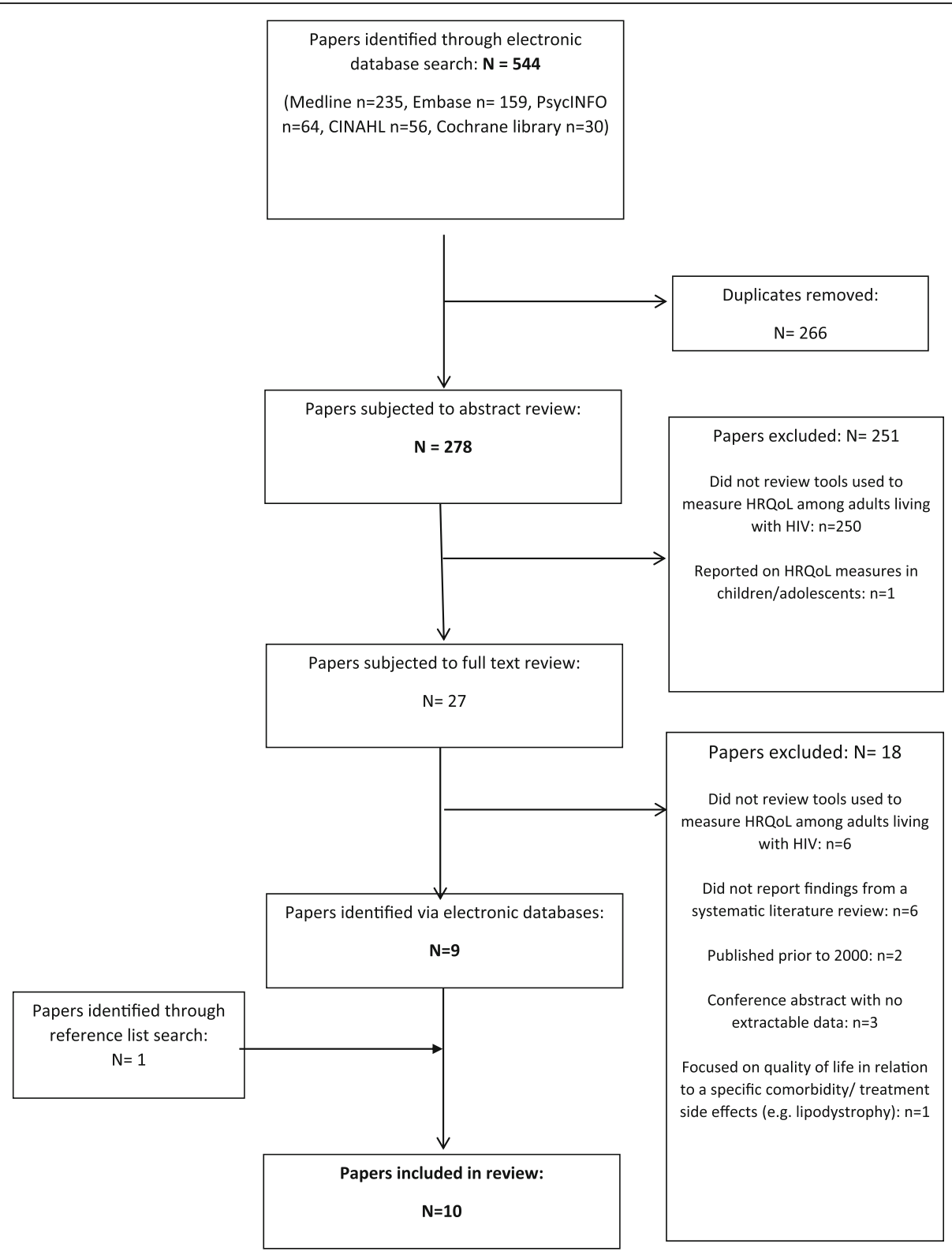

Fig. 1 PRISMA Flow diagram showing paper selection process

and full text review and indicated how disagreements between the reviewers were resolved. No reviews included a quality assessment. Two reviews listed the studies they included along with descriptions of their key characteristics. None of the reviews assessed publication bias. The criterion 'was heterogeneity assessed' [16] was not applicable because none of the reviews included a meta-analyses.

\section{Selection of measures for further scrutiny Generic measures}

Twenty-nine generic HRQoL measures were reviewed against the inclusion criteria (Fig. 2). Of those, 10 were not comprehensive, 2 were not self-administered, 7 took longer than $10 \mathrm{~min}$ to complete/ had 40 or more items and 1 had no normative data and were therefore excluded. Nine generic measures met the inclusion criteria and were retained for further analysis. These were the COOP/ WONCA charts [21], EQ-5D [22, 23], FLZM Questions on Life Satisfaction [24], HUI [25], McGill Quality of life questionnaire [26], SF-12 [27], SF-20 [28], SF-36 [29-31] and WHOQOL-BREF [32,33].

\section{HIV-specific measures}

Twenty-three HIV-specific HRQoL measures were reviewed against the inclusion criteria (Fig. 3). Of those, 3 were not 


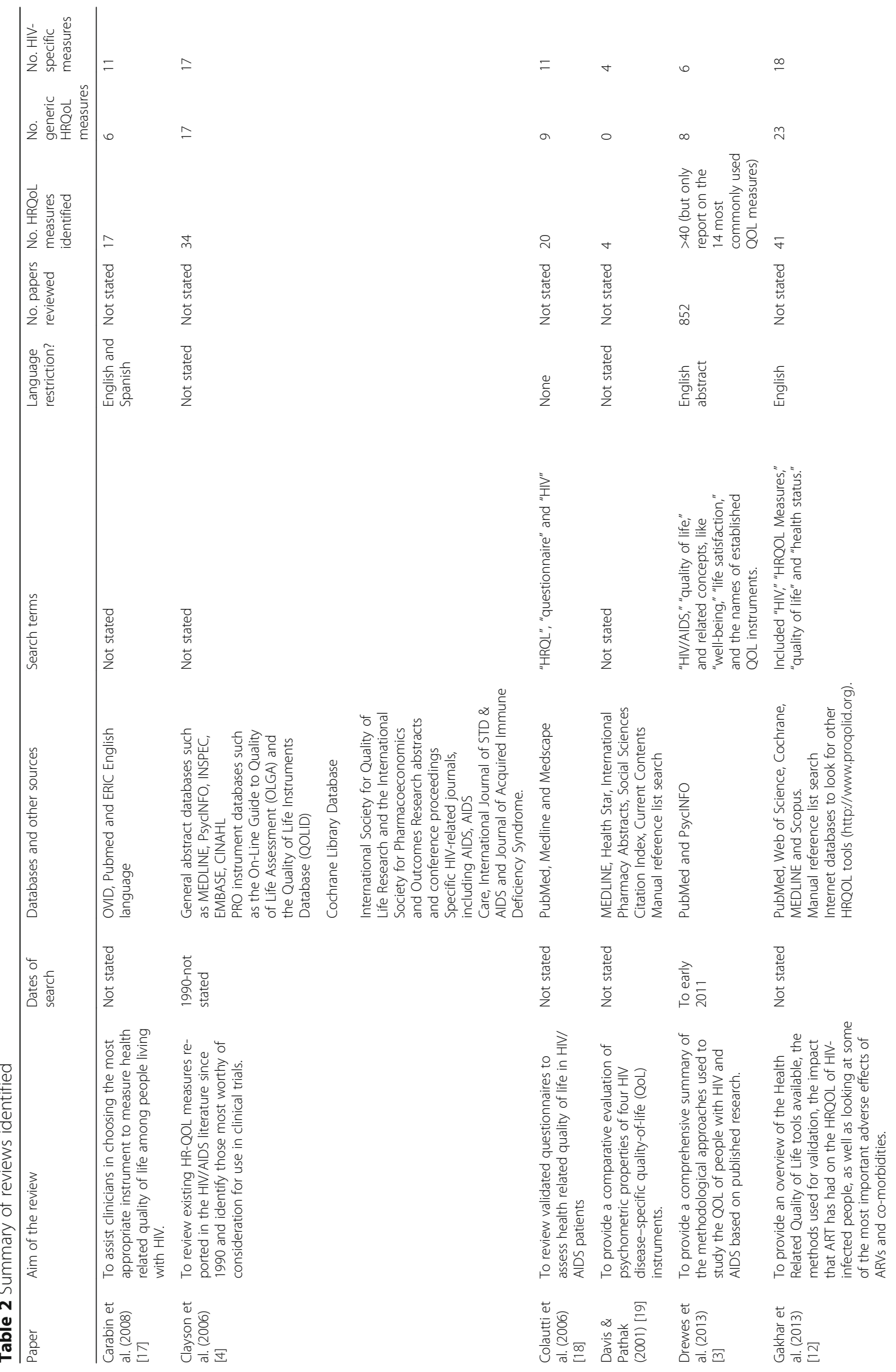




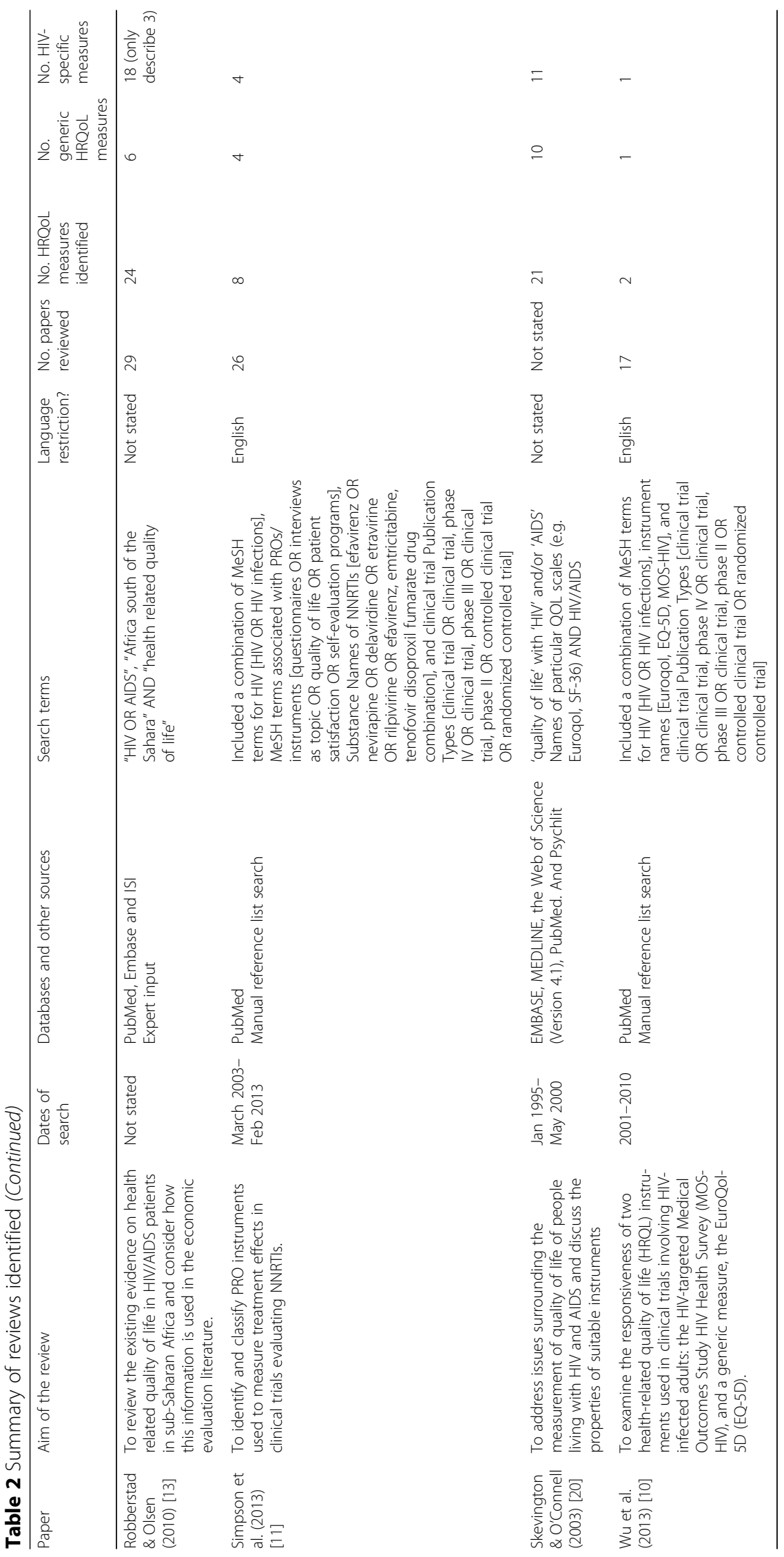




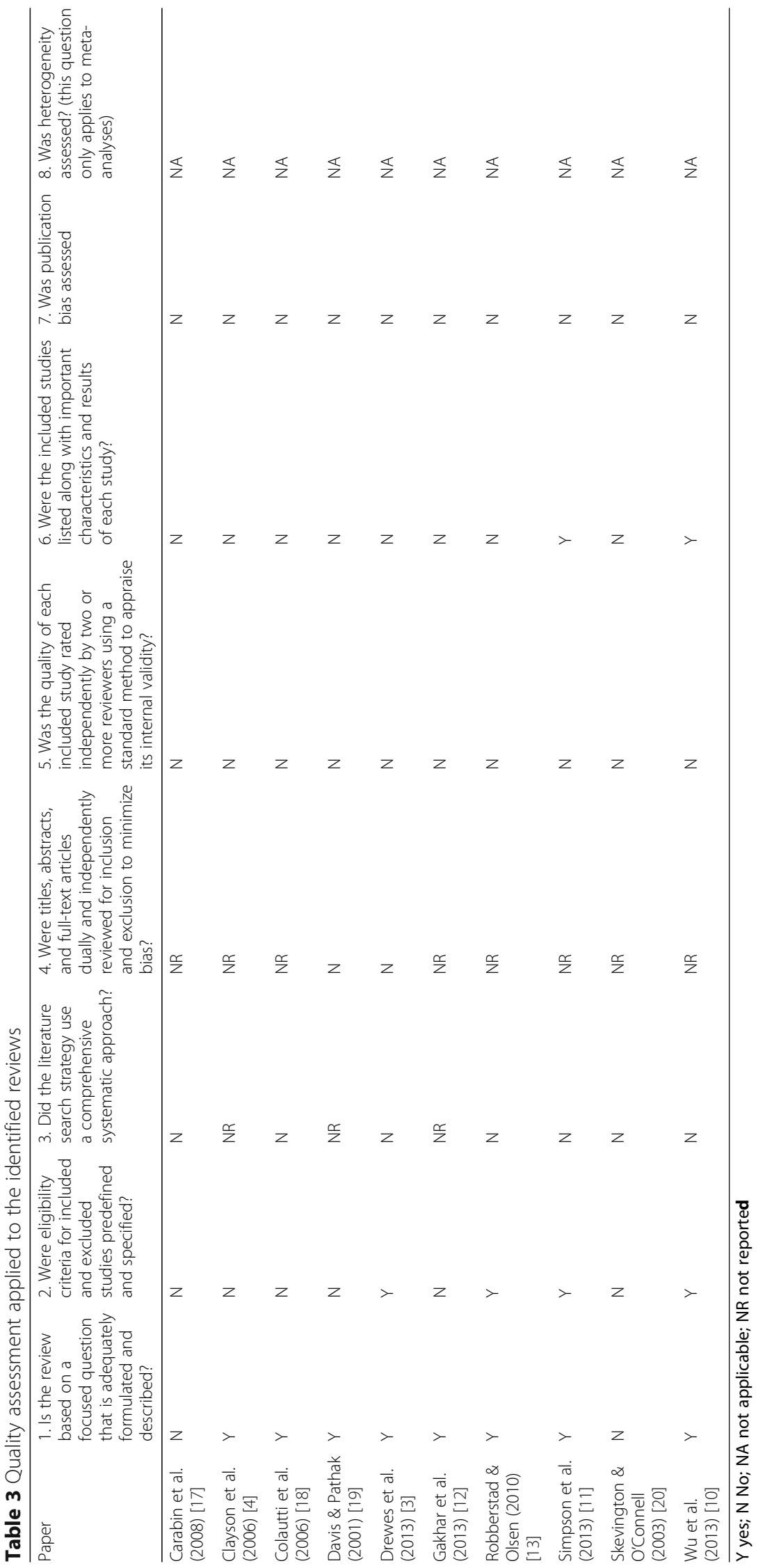




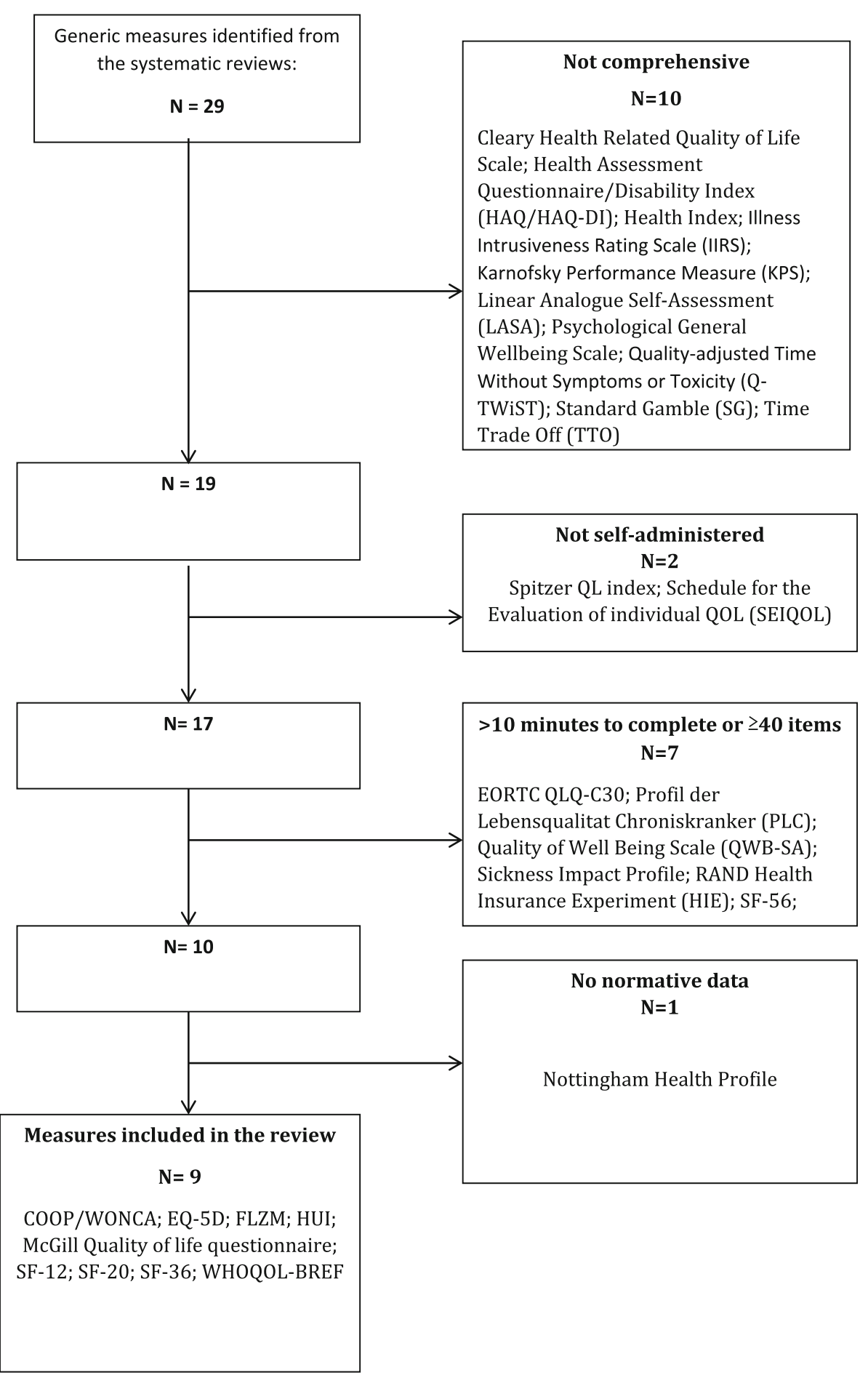

Fig. 2 Flow diagram showing selection of generic measures

comprehensive, 9 took longer than $10 \mathrm{~min}$ to complete/ had 40 or more items and there was no evidence of patient input in the development of 4 of the measures. Seven HIVspecific measures therefore met the inclusion criteria and were retained for further analysis. These were the ACTG SF-21 [34], HIV-QL31 [35], MOS-HIV [36], MQoL-HIV
[37], PROQOL-HIV [38], WHOQOL HIV-BREF [39] and HIV-SQUAD [40].

Overview of selected generic HRQoL measures

Properties of each of the generic HRQoL measures are summarised in Table 4. 


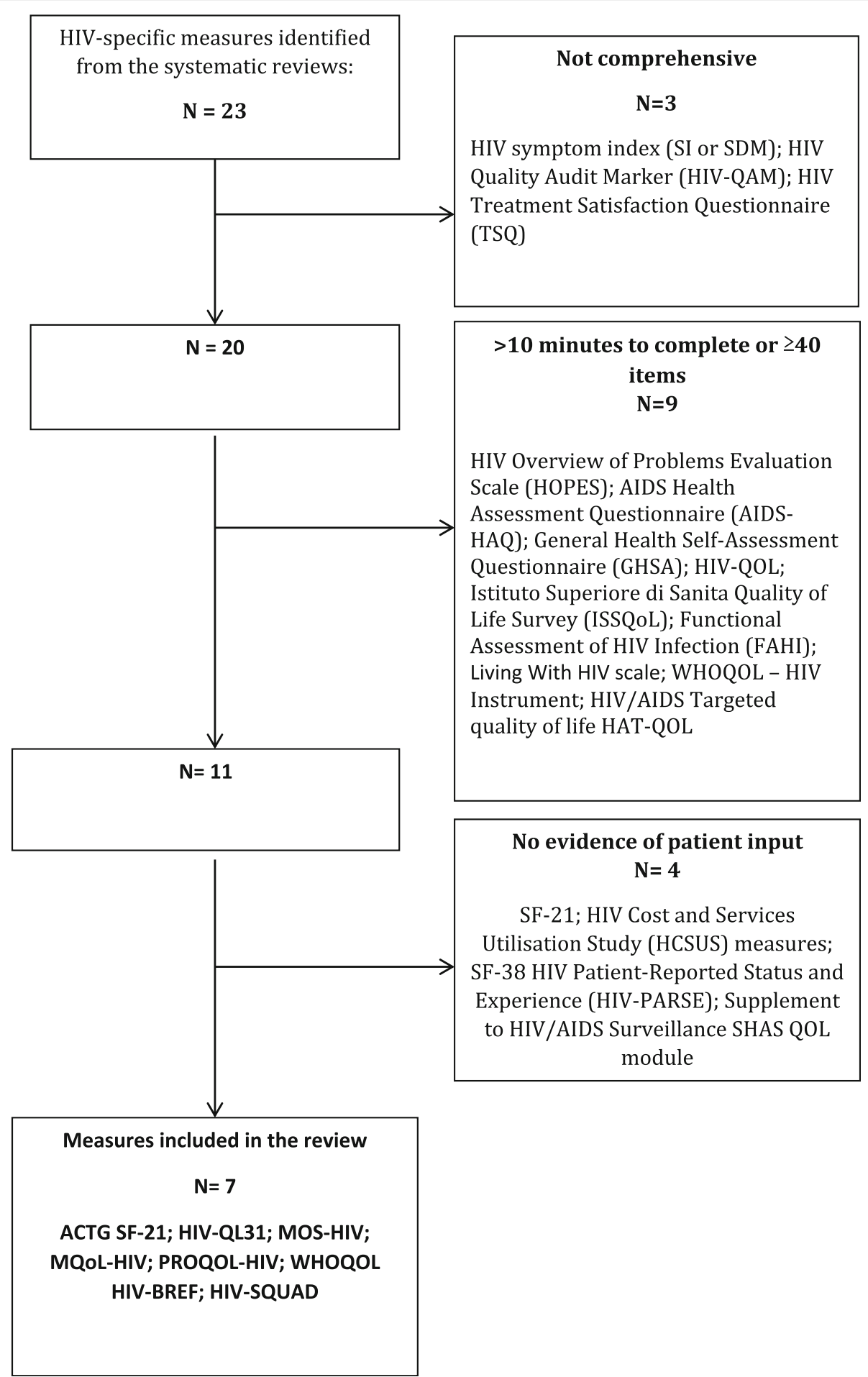

Fig. 3 Flow diagram showing selection of HIV-specific measures

\section{COOP/WONCA [21]}

The COOP/WONCA charts contain 6-9 items including the following domains: physical fitness, social activities, feelings, change in health, daily activities and overall health. Each item has five response options, presented pictorially. They are available in several languages and have been found to be acceptable to patients, however very little psychometric data were available in the reviews and they have not been widely used with people with HIV. Therefore, insufficient evidence is available to determine 


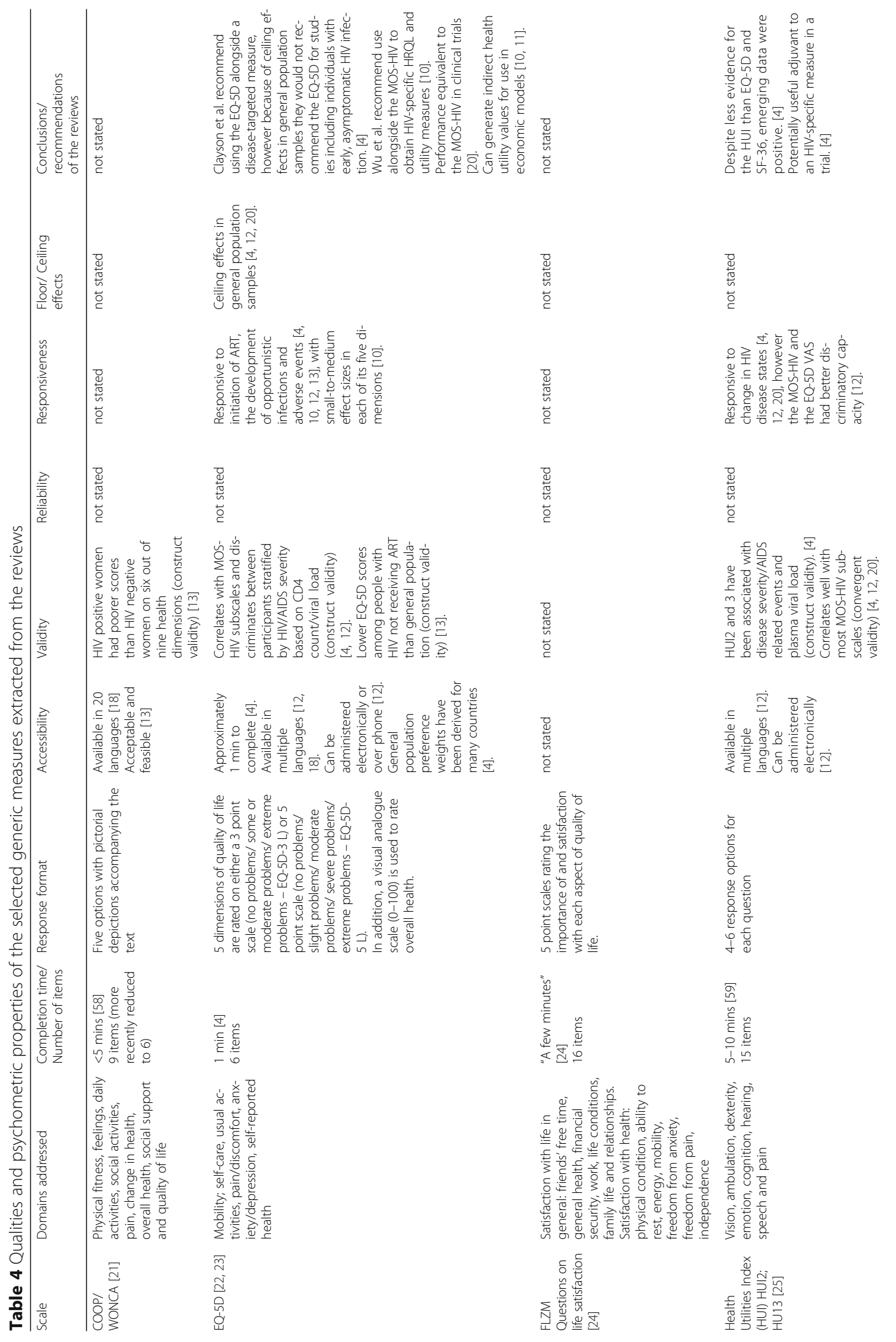




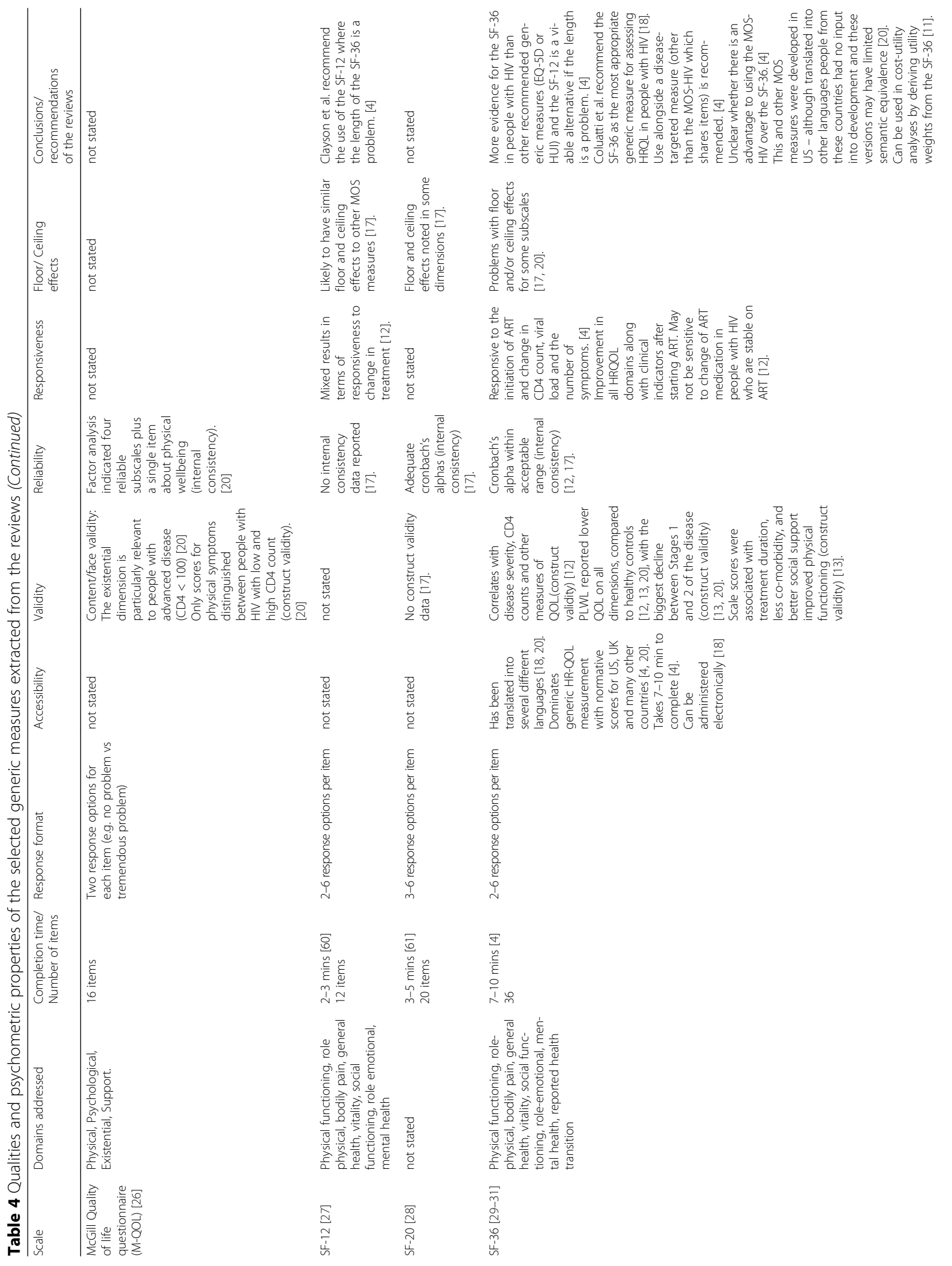




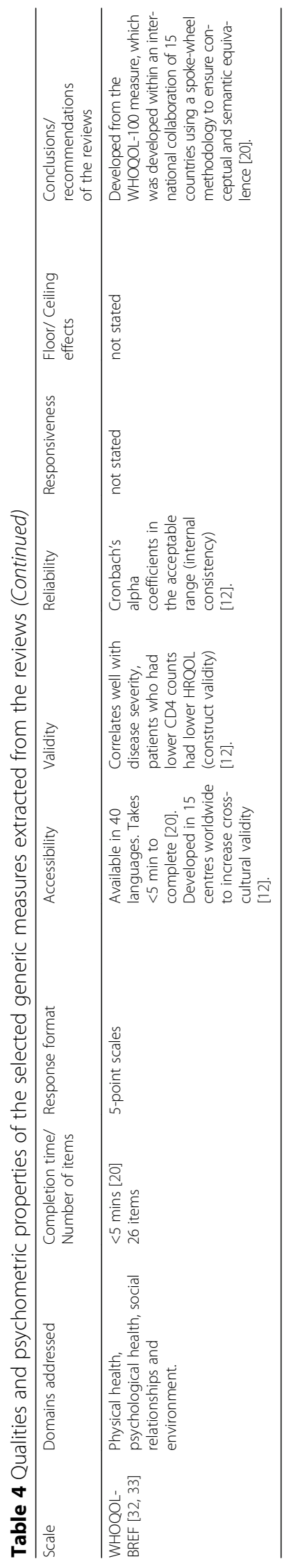


the suitability of this instrument for use in HIV research or clinical practice.

\section{$E Q-5 D[22,23]$}

The EQ-5D consists of 5 items encompassing five dimensions of quality of life (mobility, self-care, usual activities, pain/discomfort, anxiety/depression) and an optional visual analogue scale to rate overall health. It takes approximately $1 \mathrm{~min}$ to complete and is available in multiple languages. General population preference weights have been derived for many countries, enabling the use of the measure in economic analyses. The reviews provided evidence of construct and convergent validity, as well as responsiveness to treatment initiation, the development of opportunistic infections and adverse effects with small to medium effect sizes $[4,10,12,13]$. The measure has been frequently used in research with people with HIV, and several authors recommended it for use in this population $[4,10,13]$. However, problems with ceiling effects were noted $[4,20]$ therefore the use of the scale in individuals with early, asymptomatic HIV infection was not recommended [4, 19]. $\mathrm{Wu}$ et al. (2013) recommended the use of EQ-5D alongside an HIV-specific measure (the MOS-HIV) in order to obtain HIV-specific quality of life alongside this utility measure [10].

\section{Health utilities Index [25]}

The Health Utilities Index is available in two versions (HUI mark 2 (HUI2) and HUI mark 3 (HUI3)), which consist of 15/16 items respectively and assess 7 domains - vision, ambulation, dexterity, emotion, cognition, hearing, speech and pain. The measures are available in multiple languages. Although the scales have not been extensively used in HIV research, there is some evidence for their validity in this context. HUI2 and HUI3 have been associated with disease severity, AIDS-related events and viral load. [4, 12] Construct validity has been established by correlating HUI scales with the MOS-HIV [4, 20]. The scales have also been found to be responsive to change in HIV disease states $[12,20]$ however, both the MOS-HIV and EQ-5D have been found to have better discriminatory capacity [12]. Based on emerging data, Clayson et al. (2006) considered the HUI to be a potentially useful adjuvant to an HIV specific measure [4].

\section{The McGill quality of life questionnaire (M-QOL) [26]}

The McGill Quality of Life Questionnaire comprises 16 items encompassing four domains: support, existential well-being, physical and psychological symptoms. Skevington et al. report that the face/content validity of the measure is improved by the inclusion of an existential dimension, which may be particularly relevant to people with HIV who have advanced disease (CD4 count $<100)$ [20]. However, only scores for one subscale (physical symptoms) distinguished between people with HIV who had high and low CD4 counts, indicating poor discriminant validity of the other subscales [20]. There was a lack of information in the reviews on responsiveness or reliability. This measure has not been frequently used with people with HIV. There was therefore insufficient information available to determine the suitability of this instrument.

\section{SF-12 [27]}

The SF-12 is one of three generic measures (along with the SF-20 and SF-36) from the Medical Outcomes Study (MOS) that met our inclusion criteria. It consists of 12 items in 8 domains: physical functioning, role-physical, role-emotional, bodily pain, general health, vitality, social functioning and mental health, allowing for the generation of physical and mental health summary scores. There were little validity and reliability data available in the reviews and mixed results were presented in terms of responsiveness to change in treatment [12]. Since the SF-12 shares items with other measures developed from the MOS, it was considered likely that the scale had similar floor and ceiling effects to other MOS scales [17]. Clayson et al. recommended the use of the SF-12 in place of the SF-36 where the length of the SF-36 is a problem [4].

\section{SF-36 [29-31]}

The SF-36 comprises 36 items encompassing 9 domains: physical functioning, role-physical, bodily pain, general health, vitality, social functioning, role-emotional, mental health and reported health transition allowing for the generation of physical and mental health summary scores. The scale has been translated into several languages and takes approximately $10 \mathrm{~min}$ to complete. Scores on the SF-36 can be used in economic analyses by deriving utility weights [11]. The original SF-36 [28] was modified to improve the range and precision of some of the scales, improve the wording and format of the questionnaire, resulting in the SF-36 v2 [41], however the reviews largely failed to distinguish between the two versions. As a result, this review refers only to the SF-36 and does not specify whether the findings relate to Version 1 or Version 2. The reviews reported good to acceptable internal consistency and construct validity [13, 20]. People with HIV reported lower HRQoL on all dimensions compared to general population controls $[13,20]$. Scale scores have been associated with treatment duration, less comorbidity and better social support [13]. The SF-36 has been found to be responsive to the initiation of ART, change in CD4 count, viral load and symptoms $[4,12,20]$ however it may not be sensitive to change in ART medication in patients who are 
stable on ART [12]. Problems with floor and/or ceiling effects have been reported on some subscales [20]. The SF-36 was recommended for use in people with HIV in two of the reviews $[4,18]$, however a criticism of this and other MOS measures was that they were developed in US and translated into other languages without the input of patients to ensure conceptual and semantic equivalence, and therefore may not be relevant for use in cross-sectional research [20].

\section{WHOQOL-BREF $[32,33]$}

The WHOQOL-BREF was developed from the WHOQOL100 instrument, which was produced within an international collaboration of 15 countries, using a spoke-wheel methodology to ensure conceptual and semantic equivalence across languages and cultures [20]. The instrument has been frequently used in people with HIV. It consists of 26 items over 4 domains: physical health, psychological health, social relationships and environment. It is available in 40 languages and takes less than 5 min to complete [20]. Good psychometric properties, including Cronbach's alpha coefficients in the acceptable range, correlations with disease severity and CD4 count were reported $[12,20]$, however data on responsiveness were not available in the reviews.

Two additional instruments, the FLZM [24] and the SF-20 [28], were identified (Table 4), however the reviews did not assess their psychometric properties. There was insufficient information available to determine the suitability of these instruments.

\section{Overview of selected HIV specific HRQoL measures}

Properties of each of the HIV-specific HRQoL scales are summarised in Table 5.

\section{ACTG-SF21 [34]}

The ACTG-21 consists of 21 items encompassing 7 HRQoL domains: physical functioning, energy/fatigue, social functioning, cognition, pain, health perception and emotional wellbeing. The reviews did not report reliability or validity data for the scale but floor and ceiling effects were anticipated given that the scale shares items with other MOS measures [17]. The measure has not been widely used in people with HIV. There was therefore insufficient information available to determine the suitability of this measure.

\section{HIV-QL-31 [35]}

The HIV-QL-31 is a 31-item measure encompassing the following domains: sex life, pain, psychological aspects, relationships, limitations caused by HIV, symptoms and impact of treatment and care. The scale has high internal consistency $[17,20]$ and has been shown to discriminate between groups based on disease severity [20]. The measure was developed with patients and thereby covers a broad range of issues relevant to people with HIV [20]. However the HIV-QL-31 has not been widely used and the limited psychometric data available, including lack of information on responsiveness, make it difficult to establish the suitability of this measure.

\section{MOS-HIV [36]}

The MOS-HIV is most widely used HIV-specific measure. Initially based on the SF-20, it consists of 35 items across 11 domains: physical functioning, pain, social functioning, role functioning, emotional well-being, energy/fatigue, cognitive function, health distress, health transition, general health and overall quality of life, allowing for the generation of physical and mental health summary scores. The instrument has been translated into at least 14 languages. The English version takes approximately 5-10 min to complete, but was reported to take twice as long for some translations, such as the Spanish version, where more words are required to express the concepts [20]. Scoring and interpretation has been described as complex [12, 20].

The reviews reported mixed findings on the psychometric properties of the MOS-HIV. Good internal consistency was generally reported $[4,12,19,20]$ however Carabin et al. reported acceptable internal consistency for some but not all domains [17]. Testretest reliability was considered inadequate $[17,19]$. The reviews contained mixed findings regarding construct validity, with some suggesting poor construct validity [17] and others suggesting good construct validity [20]. Acceptable convergent and discriminant validity was reported in several reviews [4, 12], however some studies did not find the expected relationship with CD4 count [12, 20]. Responsiveness has been established in a wide variety of contexts including adverse events, increased symptoms, opportunistic infections, AIDS defining events and initiation of ART [4, $10,12,18,19]$, however negligible effects have been found in patients changing ART regimens [10]. Gakhar et al. found the MOS-HIV to be more responsive than the EQ-5D and HUI3 [12]. However, ceiling effects have been reported on several domains $[19,20]$.

Overall, the MOS-HIV was considered to have wellestablished psychometric properties. It was recommended as a suitable measure for assessing HRQoL in people with HIV $[4,10,18]$, either individually or together with the EQ-5D [10]. However reservations expressed in the reviews included concerns about the continued relevance of the measure for people with HIV, given that it was one of the earliest HIV-specific scales to be developed [4], questions about whether there was a true advantage of 


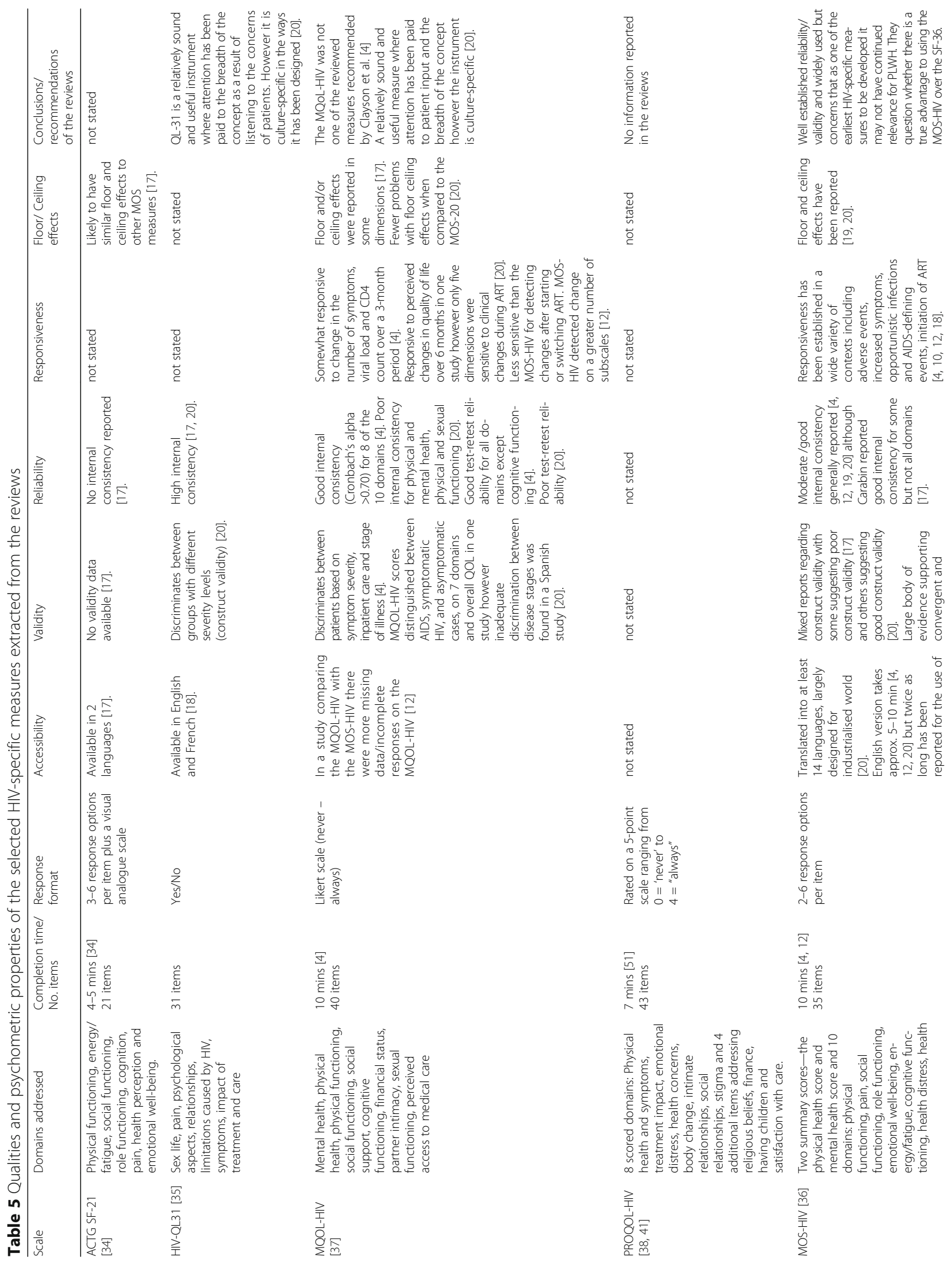




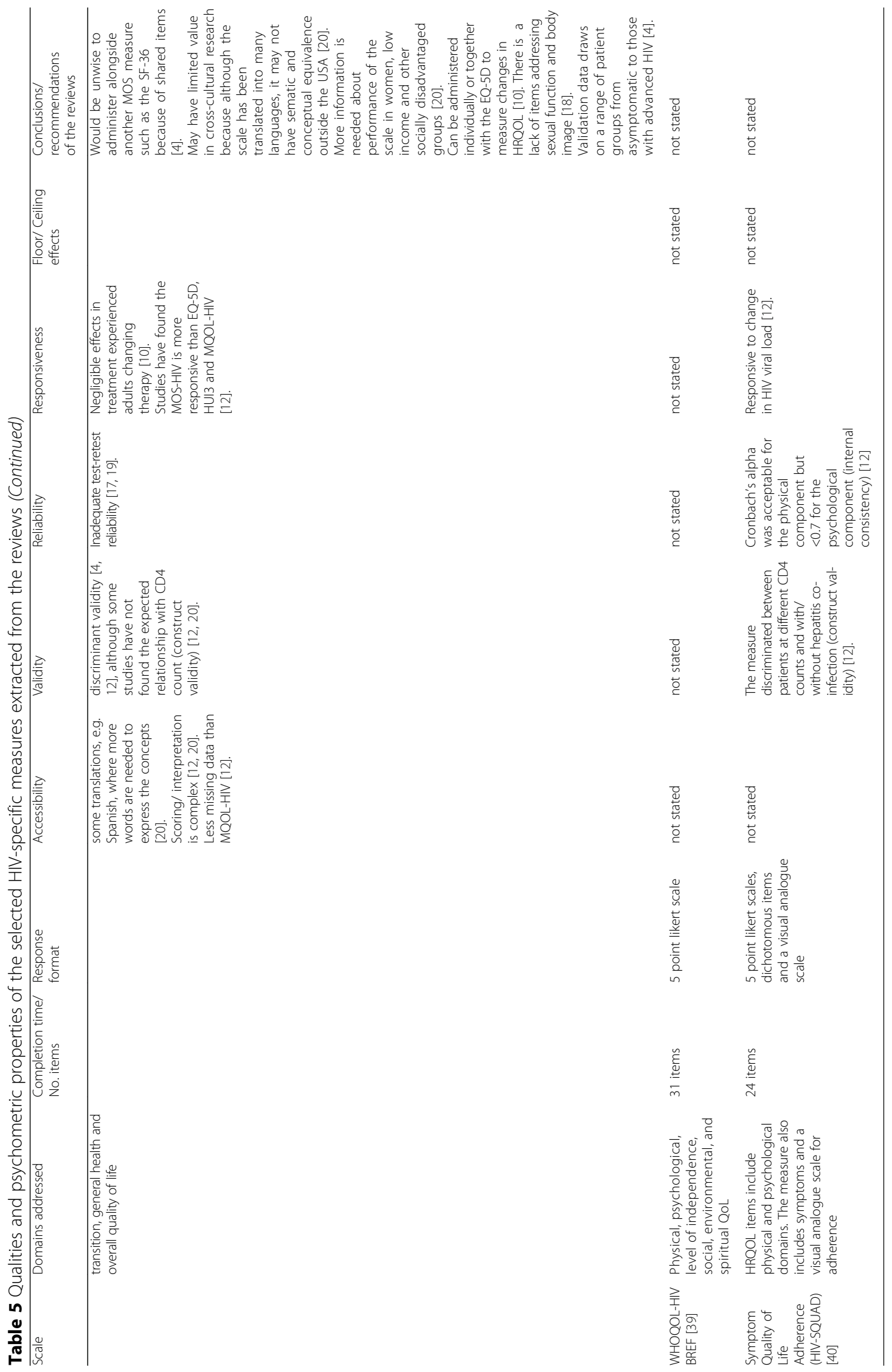


using the MOS-HIV over the SF-36 [4] and scepticism about the 'gold standard' status that has been assigned to the MOS-HIV based on available evidence [20]. One criticism was that while patient interviews were conducted as part of the development process, they had not sampled extensively from people with HIV, limiting content validity [20]. Furthermore, like the SF-36, the MOS-HIV may lack conceptual relevance across different languages and cultures [20]. The need for more information about the performance of the scale in women, low income and disadvantaged groups was also identified [20].

\section{Multidimensional quality of life questionnaire for persons with HIV/AIDS (MQOL-HIV) [37]}

The MQOL-HIV consists of 40 items assessing 10 domains: physical health, physical functioning, mental health, social functioning, cognitive functioning, social support, financial status, sexual functioning, partner intimacy and access to care. These domains were developed through interviews with HIV positive patients and providers in different settings.

The MQOL-HIV was considered to be a useful instrument since attention had been paid to the concerns of people living with HIV in its development [20], however there was limited evidence to support the construct validity, reliability and responsiveness of this instrument $[4,12,20]$ and floor and/or ceiling effects were reported in some domains [17].

\section{PROQOL-HIV [38, 42]}

The PROQOL-HIV consists of 43 items assessing 8 domains: physical health and symptoms, treatment impact, emotional distress, health concerns, body change, intimate relationships, social relationships and stigma. The items were developed through interviews conducted with people living with HIV in 9 countries. Psychometric data were not reported in the reviews.

\section{Symptom quality of life adherence (HIV-SQUAD) [40]}

The HIV-SQUAD consists of 24 items assessing HRQoL, a symptom checklist and a visual analogue scale to measure adherence. Preliminary psychometric data were reported in one review [12]. While Cronbach's alphas indicted acceptable internal consistency for the physical component, there was unacceptable internal consistency for the psychological component. The instrument was able to discriminate between patients with different illness states (CD4 count, hepatitis infection) and was responsive to changes in HIV viral load [12]. However, there was no evidence of the measure's use beyond the initial validation paper and limited psychometric data were available in the reviews.

\section{WHOQOL-HIV BREF [39]}

The WHOQOL-HIV BREF was developed in focus groups of people with HIV across 6 countries, ensuring that the items have conceptual and semantic relevance across cultures [20]. The instrument has 31 items, including several developed as a result of input from people with HIV (e.g. sexual activity, social inclusions and aspects of spirituality, such as forgiveness) and covers the six generic WHOQOL domains (physical functioning, psychological functioning, levels of independence, social relationships, environment and spirituality). No psychometric data on the scale were available in the reviews.

\section{Discussion}

The aim of this review was to identify brief, appropriately validated, pragmatic tools for assessing HRQoL in HIV interventions and clinical care, by synthesising the findings of previous reviews on this topic. Both generic and HIV-Specific HRQoL instruments were identified.

Of the 10 generic measures, the EQ-5D, SF-36 and WHOQOL-BREF appear to be the most extensively used in HIV research. The reviews provided psychometric data to support the use of the EQ-5D and SF-36. A major advantage of the EQ-5D is its brevity, enabling most patients to complete the instrument approximately a minute. However, a limitation of the EQ-5D reported in the reviews was the potential ceiling effect. Indeed in one RCT, $40 \%$ patients obtained the highest possible score [43]. However, the papers included all reviewed studies using the original three level version of the EQ$5 \mathrm{D}$, whereby patients had three response options for each item (no problems/ some or moderate problems/ extreme problems). A revised five level version is now available (no problems/ slight problems/ moderate problems/ severe problems/ extreme problems) which has demonstrated good psychometric qualities including acceptable internal consistency and a reduced ceiling effect among people with HIV [44].

The benefits of these generic HRQoL instruments include the availability of normative data allowing comparison of HRQOL with other groups, and the ability to examine the impact of HIV and comorbid conditions on HRQOL in a single assessment. Furthermore utility weights can be derived from both the EQ-5D and SF-36 enabling their use in economic analyses. However, generic measures may be less sensitive to changes in disease or treatment than HIV-specific instruments [11].

Of the HIV-specific measures, only the MOS-HIV was supported by sufficient psychometric data in the reviews, although there was some concern about 
limited input from people with HIV, cultural relevance and its continued applicability since the introduction of ART. Two more recently developed HIV-specific measures, the WHOQOL-HIV BREF and the PROQOLHIV, were identified in the reviewed papers but their psychometric properties were not described.

A paper outlining the development and initial validation of the WHOQOL-HIV BREF was published in 2012 [39], reporting good internal consistency and discriminant validity. The authors highlighted the importance of the spirituality/personal beliefs and independence domains, often overlooked in quality of life research. They acknowledged the need for further validation, including in studies with longitudinal designs. Subsequent cross-sectional research has provided evidence of the measure's psychometric properties in a range of populations including people with HIV in Portugal [45, 46], Taiwan [47], Malaysia [48], Vietnam [49] and Iran [50]. Preliminary evidence of its responsiveness comes from a prospective study of patients initiating ART in China, where significant improvements in QOL in all WHOQOL-HIV BREF domains were observed over the first six months of treatment [51].

The PROQOL-HIV was developed with extensive input from people living with HIV across nine countries [38]. It has been validated in a large cross-sectional multi-cultural study, demonstrating good internal consistency and construct validity [42]. In addition, satisfactory test-retest reliability has been established in a smaller sample [42]. An electronic version of the PROQOL-HIV has been found to be reliable and acceptable to patients [52]. Again, there is currently limited published research assessing the responsiveness of the PROQOL-HIV, although a recent trial reported a significant increase in scores on the body change, social relationships and emotional distress subscales following an online self-management intervention [53]. The PROQOL-HIV and WHOQOL-HIV BREF are increasingly being used in HIV research and may prove to be psychometrically sound and culturally valid alternatives to the MOS-HIV.

One strategy recommended within the reviews was to use a generic measure alongside an HIV-specific instrument $[4,10]$, such as the EQ-5D and the MOS-HIV [10]. Due to overlap in items it would not be appropriate to use the SF-36 alongside the MOS-HIV [4].

This review adds value to the literature by synthesising the findings of existing reviews of HRQoL measures used in HIV, including the findings of recent reviews on the subject $[3,10-12]$ which had various aims, for example to identify frequently used instruments [3]; determine how instruments have been applied to ART utilisation [12], identify measures used in a specific treatment context [11] and determine the responsiveness of specific instruments [10]. As with all reviews, we were limited by the data available in the included papers. The results of the quality assessment indicated that many of the reviews were of a poor quality, with most lacking a comprehensive search or identification/selection of papers by independent reviewers. No recent reviews with searches conducted since 2013 were identified. It is possible that new measures of quality of life could have been validated for use in people with HIV since this time. For example, a shorter version of the WHOQOL- BREF has subsequently been developed (EUROHIS-QOL-8) [54] but as yet there are insufficient validation data to recommend this measure.

For this review our aim was to identify brief measures for use in a busy clinic or repeated measures study. However, there may be HRQoL tools available that take longer than $10 \mathrm{~min}$ to complete or have more than 40 items but are still acceptable to patients and clinicians in the HIV care setting. For example the Functional Assessment of Human Immunodeficiency Virus Infection (FAHI [55]; 47 items, <15mins completion time [4, 56]) was viewed favourably in the review by Clayson and colleagues [4] and may be appropriate, although others have suggested it is too long and difficult to score for use in a clinical setting [57]. Further research is required to establish acceptability, which was rarely mentioned in the reviews. The selection of a HRQoL measure for use in research or clinical practice is also likely to be influenced by cost and the need to buy a licence. The reviews included in this review did not include information on the cost of the various instruments, therefore no licencing or cost information has been included in the current review.

The choice of one HRQoL measure over another is likely to be influenced by the purpose of the quality of life assessment and the domains of HRQoL that are most relevant to the specific research or clinical question. For example, responsiveness is essential where the aim is to evaluate treatment. Our review provided evidence of responsiveness for the EQ-5D, SF-36 and MOS-HIV. For clinical practice, it is important that a wider range of requirements are met, for example it is important that the scale is valid and reliable, but also simple to complete and score and easily interpretable [58]. The MOS-HIV and SF-36 include several different rating scales and response options, which could make scoring complex [20]. While psychometric data were lacking in the reviews, subsequent research suggests that the WHOQOL-HIV BREF and PROQOL-HIV may prove to be the most cross-culturally valid measures and therefore a good choice for international assessment of HRQOL in HIV.

\section{Conclusion}

This systematic review of reviews identified several validated generic and HIV specific pragmatic tools for 
assessing HRQoL in HIV interventions and clinical care. The measures supported with most psychometric evidence in the systematic reviews were the EQ-5D, SF-36, WHOQOL-BREF and MOS-HIV. More recently developed HIV specific scales, including the PROQOL HIV and WHOQOL BREF-HIV may prove to be the most cross-culturally valid. Ultimately, the selection of a HRQoL measure is likely to be influenced by the context in which it is to be used.

\section{Abbreviations}

ART: Antiretroviral therapy; NHS: National Health Service; NIHR: National Institute for Health Research; UK: United Kingdom

\begin{abstract}
Acknowledgements
This paper is dedicated to Professor Martin Fisher, our much missed colleague and friend, who died in April 2015. Together with Dr. Jenny Whetham, Martin conceived the idea, designed and secured funding for EmERGE programme. Thanks to Nicky Perry for helpful comments on an early draft. This paper summarises independent research funded by the European Union's Horizon 2020 research and innovation programme under grant agreement No 643736. The scientific members of the EmERGE consortium are Adrian Brown; Agathe Leon; Ben Marent; Brian West; Cesar Caceres; Daniel Lockhart; David Garcia; Duncan Fatz; Ed Wallitt; Eduard Beck; Enrique Gomez; Eugenio Teofilo; Eva Gonzalez; Felipe Garcia; FlisHenwood; Goncalo Rodrigues; Jennifer Whetham; Josip Begovac; Koen Block; Letitia Pereira; Ludwig Apers; Margarida Borges; Mary Darking; Paloma Chausa; Sime Zekan; Steven Bremner; Steven Hoornaert, Sundhiya Mandalia.
\end{abstract}

\section{Availability of data and materials}

The datasets analysed during the current study are available from the corresponding author on reasonable request

\section{Authors' contributions}

JW and the EmERGE Consortium were responsible for the acquisition of funding. All authors were responsible for the conception and design of the study. JC and VC conducted the systematic review collection of data. All authors, were involved with drafting and revising the manuscript and approval of the final version.

\section{Funding}

EmERGE is a project funded by the European Union's Horizon 2020 Research and Innovation Programme under Grant agreement no: 643736.

The dissemination activities within the EmERGE project do not represent the opinion of the European Community and only reflect the opinion of the authors and / or the Consortium.

\section{Ethics approval and consent to participate}

No ethics approval was required for this systematic review.

\section{Consent for publication}

Not applicable.

\section{Competing interests}

This paper summarises independent research funded by European Union's Horizon 2020 research and innovation programme. The authors declare that they have no competing interests.

\section{Publisher's Note}

Springer Nature remains neutral with regard to jurisdictional claims in published maps and institutional affiliations.

\section{Author details}

${ }^{1}$ The Lawson Unit, Brighton and Sussex University Hospitals NHS Trust, Eastern Road, Brighton BN2 1HS, UK. Department of Palliative Care, Policy and Rehabilitation, King's College London, Faculty of Life Sciences and Medicine, Cicely Saunders Institute, Bessemer Road, London SE5 9PJ, UK.
Received: 19 March 2017 Accepted: 5 October 2017

Published online: 15 November 2017

\section{References}

1. Nakagawa F, Lodwick RK, Smith CJ, et al. Projected life expectancy of people with HIV according to timing of diagnosis. AIDS. 2012;26(3):335-43.

2. Miners A, Phillips A, Kreif N, et al. Health-related quality-of-life of people with HIV in the era of combination antiretroviral treatment: a cross-sectional comparison with the general population. Lancet HIV. 2014;1(1):e32-40.

3. Drewes J, Gusy B, Von U. More than 20 years of research into the quality of life of people with HIV and AIDS - a descriptive review of study characteristics and methodological approaches of published empirical studies. Journal of the International Association of Providers of AIDS Care. 2013;12(1):18-22.

4. Clayson DJ, Wild DJ, Quarterman P, Duprat-Lomon I, Kubin M, Coons SJA. A comparative review of health-related quality-of-life measures for use in HIV/ AIDS clinical trials. PharmacoEconomics. 2006;24(8):751-65.

5. Bakas T, McLennon SM, Carpenter JS, et al. Systematic review of healthrelated quality of life models. Health Qual Life Outcomes. 2012;10(1):1-12.

6. World Health Organisation. Basic Documents. Forty Eighth Edition. 2014. http://apps.who.int/gb/bd/PDF/bd48/basic-documents-48th-edition-en.pdf page $=7$. (Accessed March 2016).

7. Fayers P, Machin D. Quality of life: the assessment, analysis and interpretation of patient reported outcomes. Second edition ed. Chichester: Wiley; 2007

8. World Health Organisation. The World Health Organization quality of life assessment (WHOQOL): position paper from the World Health Organization. Soc Sci Med. 1995;41(10):1403-9.

9. UNAIDS. National AIDS Programmes: A guide to monitoring and evaluation. 2000. http://www.who.int/hiv/pub/epidemiology/en/JC427-Mon_Ev-Full_en. pdf?ua=1. (Accessed March 2016).

10. Wu AW, Hanson KA, Harding G, et al. Responsiveness of the MOS-HIV and EQ-5D in HIV-infected adults receiving antiretroviral therapies. Health Qual Life Outcomes. 2013;11:42.

11. Simpson KN, Hanson KA, Harding G, et al. Patient reported outcome instruments used in clinical trials of HIV-infected adults on NNRTI-based therapy: a 10-year review. Health Qual Life Outcomes. 2013:11(1)

12. Gakhar H, Kamali A, Holodniy M. Health-related quality of life assessment after antiretroviral therapy: a review of the literature. Drugs. 2013;73(7):651-72.

13. Robberstad B, Olsen JA. The health related quality of life of people living with HIV/AIDS in sub-Saharan Africa - a literature review and focus group study. Cost Effectiveness and Resource Allocation. 2010;8:5.

14. Smith V, Devane D, Begley CM, Clarke M. Methodology in conducting a systematic review of systematic reviews of healthcare interventions. BMC Med Res Methodol. 2011;11(1):15

15. Moher D, Liberati A, Tetzlaff J, Altman DG. Preferred reporting items for systematic reviews and meta-analyses: the PRISMA statement. BMJ. 2009;339

16. National Heart Lung and Blood Institute. Quality Assessment of Systematic Reviews and Meta-Analyses. 2014. http://www.nhlbi.nih.gov/health-pro/ guidelines/in-develop/cardiovascular-risk-reduction/tools/sr_ma. (Accessed March 2016).

17. Carabin H, Sonleitner NK, Keesee M, Shinault K. Quality of life measurement tools for people living with HIV/AIDS. Journal of HIV/AIDS \& Social Services. 2008;7(1):71-83

18. Colautti M, Palchik V, Botta C, Salamano M, Traverso ML. Review of questionnaires to assess health related quality of life in HIV patients [Spanish] revision de cuestionarios para evaluar calidad de vida relacionada a la salud en pacientes VIH/Sida. Acta Farm Bonaer. 2006;25(1):123-30.

19. Davis EA, Pathak DS. Psychometric evaluation of four HIV disease-specific quality-of-life instruments. Ann Pharmacother. 2001;35(5):546-52.

20. Skevington SM, O'Connell KA. Measuring quality of life in HIV and AIDS: a review of the recent literature. Psychol Health. 2003;18(3):331-51.

21. Nelson E, Wasson J, Kirk J, et al. Assessment of function in routine clinical practice: description of the COOP chart method and preliminary findings. J Chronic Dis. 1987;40(Suppl 1):55S-695.

22. Brooks R. EuroQol: the current state of play. Health Policy. 1996;37(1):53-72.

23. EuroQol Group. EuroQol -a new facility for the measurement of healthrelated quality of life. Health Policy. 1990;16(3):199-208.

24. Henrich G, Herschbach P. Questions on life satisfaction (FLZM) - a short questionnaire for assessing subjective quality of life. Eur J Psychol Assess. 2000;16(3):150-9. 
25. Horsman J, Furlong W, Feeny D, Torrance G. The health utilities index (HUI): concepts, measurement properties and applications. Health Qual Life Outcomes. 2003;1:54.

26. Cohen SR, Hassan SA, Lapointe BJ, Mount BM. Quality of life in HIV disease as measured by the McGill quality of life questionnaire. AIDS. 1996;10(12):1421-7.

27. Ware JE Jr, Kosinski M, Keller SD. A 12-item short-form health survey: construction of scales and preliminary tests of reliability and validity. Med Care. 1996;34(3):220-33.

28. Ware JE Jr, Sherbourne CD, Davies AR. Developing and testing the MOS 20-item short-form health survey: a general population application. In: Stewart AL, Ware JE, editors. Measuring functioning and well-being: the medical outcomes study approach. Durham, NC: Duke University Press; 1992. p. 277-90.

29. Ware JE Jr, Sherbourne CD. The MOS 36-item short-form health survey (SF-36). I. Conceptual framework and item selection. Med Care. 1992;30(6):473-83.

30. McHorney CA, Ware JE Jr, Raczek AE. The MOS 36-item short-form health survey (SF-36): II. Psychometric and clinical tests of validity in measuring physical and mental health constructs. Med Care. 1993;31(3):247-63.

31. McHorney CA, Ware JE Jr, JF L, Sherbourne CD. The MOS 36-item short-form health survey (SF-36): III. Tests of data quality, scaling assumptions, and reliability across diverse patient groups. Med Care. 1994;32(1):40-66.

32. Skevington SM, Lotfy M, O'Connell KA, Group W. The World Health Organization's WHOQOL-BREF quality of life assessment: psychometric properties and results of the international field trial. A report from the WHOQOL group. Qual Life Res. 2004;13(2):299-310.

33. WHOQOL Group. Development of the World Health Organization WHOQOL-BREF quality of life assessment. The WHOQOL group. Psychol Med. 1998;28(3):551-8

34. AIDS Clinical Trials Group Outcomes Committee. ACTG Quality of Life 601602 Health Survey Manual. 1999. https://www.fstrf.org/apps/cfmx/apps/ common/QOLAdherenceForms/resources/actg/manualql601-2799.pdf. (Accessed March 2016).

35. Leplege A, Rude N, Ecosse E, Ceinos R, Dohin E, Pouchot J. Measuring quality of life from the point of view of HIV-positive subjects: the HIV-QL31. Qual Life Res. 1997;6(6):585-94.

36. Wu AW. MOS-HIV health survey users manual. 1999. File:///C:/users/Jane/ downloads/MOS_HIV_Health_Survey.Pdf. (Accessed March 2016).

37. Smith KW, Avis NE, Mayer KH, Swislow L. Use of the MQoL-HIV with asymptomatic HIV-positive patients. Qual Life Res. 1997;6(6):555-60.

38. Duracinsky M, Herrmann S, Berzins B, et al. The development of PROQOL$\mathrm{HIV}$ : an international instrument to assess the health-related quality of life of persons living with HIV/AIDS. Journal of acquired immune deficiency syndromes (1999). 2012;59(5):498-505.

39. O'Connell KA, Skevington SM. An international quality of life instrument to assess wellbeing in adults who are HIV-positive: a short form of the WHOQOL-HIV (31 items). AIDS Behav. 2012;16(2):452-60.

40. Spire B, Arnould B, Barbier F, et al. Simplification and first validation of a short battery of patient questionnaires for clinical management of HIVinfected patients: the HIV-SQUAD (symptom quality of life adherence) questionnaire. HIV clinical trials. 2009;10(4):215-32.

41. Jenkinson C, Stewart-Brown S, Petersen S, Paice C. Assessment of the SF36 version 2 in the United Kingdom. J Epidemiol Community Health. 1999:53(1):46-50.

42. Duracinsky M, Lalanne $C$, Le Coeur S, et al. Psychometric validation of the PROQOL-HIV questionnaire, a new health-related quality of life instrumentspecific to HIV disease. Journal of acquired immune deficiency syndromes (1999). 2012;59(5):506-15.

43. Huang IC, Frangakis C, Atkinson MJ, et al. Addressing ceiling effects in health status measures: a comparison of techniques applied to measures for people with HIV disease. Health Serv Res. 2008;43(1 Pt 1):327-39.

44. Tran BX, Ohinmaa A, Nguyen LT. Quality of life profile and psychometric properties of the EQ-5D-5L in HIV/AIDS patients. Health Qual Life Outcomes. 2012;10:132

45. Canavarro MC, Pereira M. Factor structure and psychometric properties of the European Portuguese version of a questionnaire to assess quality of life in HIV-infected adults: the WHOQOL-HIV-Bref. AIDS Care. 2012;24(6):799-807.

46. Pereira M, Martins A, Alves S, Canavarro MC. Assessing quality of life in middle-aged and older adults with HIV: psychometric testing of the WHOQOL-HIV-Bref. Qual Life Res. 2014;23(9):2473-9.

47. Hsiung PC, Fang $\mathrm{CT}$, CH W, et al. Validation of the WHOQOL-HIV BREF among HIV-infected patients in Taiwan. AIDS Care. 2011;23(8):1035-42.
48. Saddki N, Noor M, Norbanee T, et al. Validity and reliability of the Malay version of WHOQOL-HIV BREF in patients with HIV infection. AIDS Care. 2009;21(10):1271-8.

49. Tran BX. Quality of life outcomes of antiretroviral treatment for HIV/AIDS patients in Vietnam. PLoS One. 2012;7(7):e41062.

50. Nikooseresht Z, Rimaz S, Asadi-Lari M, Nedjat S, Merghati-Khoee E, Saiepour N. Reliability and validity of the Iranian version of the human immunodeficiency virus specific World Health Organization quality of life BREF questionnaire. Journal of Biostatistics and Epidemiology. 2015;1(1):8.

51. Ming Z, Prybylski D, Cheng F, et al. Two-year prospective cohort study on quality of life outcomes among people living with HIV after initiation of antiretroviral therapy in Guangxi, China. J Assoc Nurses AIDS Care. 2014; 25(6):603-13.

52. Duracinsky M, Lalanne C, Goujard C, et al. Electronic versus paper-based assessment of health-related quality of life specific to HIV disease: reliability study of the PROQOL-HIV questionnaire. J Med Internet Res. 2014;16(4):e115.

53. Millard T, Agius PA, McDonald K, Slavin S, Girdler S, Elliott JH. The positive outlook study: a randomised controlled trial evaluating online selfmanagement for HIV positive gay men. AIDS Behav. 2016;

54. Pereira M, Canavarro MC. Reliability and validity of the European Portuguese version of the quality of life index EUROHIS-QOL-8 in HIV-infected patients. Revista Portuguesa de Saúde Pública. 2015;33(2):183-7.

55. Peterman AH, Cella D, Mo F, McCain N. Psychometric validation of the revised functional assessment of human immunodeficiency virus infection (FAHI) quality of life instrument. Qual Life Res. 1997;6(6):572-84.

56. Beal MW, Nield-Anderson L. Acupuncture for symptom relief in HIVpositive adults: lessons learned from a pilot study. Altern Ther Health Med. 2000;6(5):33-42.

57. Webb A, Norton M. Clinical assessment of symptom-focused health-related quality of life in HIV/AIDS. J Assoc Nurses AIDS Care. 2004;15(2):67-81.

58. Higginson IJ, Carr AJ. Measuring quality of life: using quality of life measures in the clinical setting. BMJ. 2001;322(7297):1297-300.

\section{Submit your next manuscript to BioMed Central and we will help you at every step:}

- We accept pre-submission inquiries

- Our selector tool helps you to find the most relevant journal

- We provide round the clock customer support

- Convenient online submission

- Thorough peer review

- Inclusion in PubMed and all major indexing services

- Maximum visibility for your research

Submit your manuscript at www.biomedcentral.com/submit 